\title{
JURISPRUDENCIA ELECTORAL
}

\author{
POR \\ MARTIN BASSOLS COMA \\ Catedrático de Derecho Administrativo
}

\begin{abstract}
SUMARIO
I. CAMPAÑa electoral: 1. No constituye campaña electoral la actividad desarrollada por una Confederación Empresarial en pro de una determinada concepción o sistema socioeconómico: alcance subjetivo del derecho de participación política. 2. La interposición del proceso especial de la Ley 62/ 1978 en defensa del ejercicio de los Derechos Fundamentales de la Persona no queda excluida por virtud del artículo 77 del Real Decreo-ley 20/1977, sobre Normas Electorales: la no impugnación de los acuerdos de las Juntas Electorales en el proceso electoral no es una exclusión de la impugnación, sino un aplazamiento hasta el momento del proceso contencioso-electoralII. LIMITACIONES CAPACIDAD ELECTORAL PASIVA DE LOS MIEMBROS FuERZAS ARMADAS: 1. Inelegibilidad salvo obtención de la situación administrativa de retirado o situación especial. 2. No procede negar capacidad electoral pasiva a candidato, miembro Fuerzas Armadas, condenado por sentencia penal no firme, que ha solicitado pase situación retirado. Naturaleza reglada del otorgamiento dicha situación. Improcedencia derogación expresa de pase a retirado por razones oportunidad política. El artículo 117.1 de la Constitución impide reconocimiento efectos a un acto administrativo que discrimina a un candidato al estar viciado de nulidad radical como contrario a un derecho constitucional.
\end{abstract}

\section{CAMPAÑA ELECTORAL *}

1. No constituye campaña electoral la actividad desarrollada por una Confederación Empresarial en pro de una determinada concepción o sistema socieconómico: alcance subjetivo del derecbo de participación política

Que otro tanto ocurre. respecto al criterio con que en la sentencia apelada se interpretan, concretamente, los artículos 37 y 43 del citado Real Decreto-ley, número $20 / 77$, y por ello, según se expresa en la misma, lo innecesario de plantear la cuestión de su constitucionalidad, a que se refiere el artículo 35 de la Ley

* Se extracta en este epígrafe sentencia del Tribunal Supremo que confirma en recurso de apelación la de la Audiencia Nacional de 17 de junio de 1982, cuyo contenido se extracta en el número anterior de esta Revista. 
Orgánica del Tribunal Constitucional, no puede calificarse de campaña electoral, según ésta se configura en el primero de aquellos artículos (art. 37 del Real Decreto-ley núm. 20/77), la actividad desarrollada por la Confederación a que se contrae el presente proceso, en pro de una determinada concepción o sistema socioeconómico, que, con arreglo a sus estatutos, constituye uno de sus fines, lo mismo que pudieron realizarla otras agrupaciones o colectividades, de concepciones o sistemas diferentes, aunque ellos figurasen en los programas de quienes, encuadrados en el repetido artículo 37, llevaban a cabo la campaña electoral, no sólo con las obligaciones reguladas en el ordenamiento jurídico de la misma, sino también con los derechos y ventajas en él establecidos, los cuales no tenían quienes como la nombrada Confederación realizaban las actividades lícitas a que se refiere el también citado artículo 43, aplicado correctamente en la sentencia apelada. Esta interpretación de la norma electoral, como asimismo se recoge en la sentencia apelada, se halla conciliada con los preceptos constitucionales que invoca $y$, puede añadirse, también lo está, sin las limitaciones aducidas en los razonamientos del abogado del Estado, la actividad aquí contemplada de la referida Confederación, pues no hay que olvidar el encuadramiento de tales preceptos en una norma fundamental política, instauradora de un régimen democrático parlamentario, abierto, cuya primera declaración es la de radicar en el pueblo la soberanía nacional y el origen de los poderes del Estado y que propende a la participación de los ciudadanos en los asuntos públicos - art. 23- dándoles intervención directa, de modo expreso, en determinaciones, procesos, funciones y actividades -arts. 92, 105, 125 y 129-, y por ello resulta acertado el criterio con que en la sentencia apelada se interpreta el artículo 6, en el sentido de que el mismo no señala a los partidos políticos como instrumento fundamental único para la participación política de los ciudadanos. (Sentencia de la Sala IV del Tribunal Supremo de 14 de julio de 1982. Ponente: Excmo. Sr. D. Saturnino Gutiérrez de Juana.)

2. La interposición del proceso especial de la Ley 62/(1978 en defensa del ejercicio de los Derechos Fundamentales de la Persona no queda excluida por virtud del artículo 77 del Real Decreto-ley 20/1977, sobre Normas Electorales: la no impugnación de los acuerdos de las Juntas Electorales en el proceso electoral no es una exclusión de la impugnación, sino un aplazamiento basta el momento del proceso contencioso-electoral

Que las razones aducidas por el abogado del Estado, único apelante, reproducción escueta de las hechas en el curso del proceso, ante la Sala de lo ContenciosoAdministrativo de la Audiencia Nacional, y contenidos en el escrito presentado ante la misma, interponiendo la apelación, no desvirtúan los fundamentos jurídicos que sirven de base al fallo de dicha Sala, para excluir del caso la inadmisibilidad del recurso, planteada por aquella representación del Estado, porque dada la redacción del artículo 77 del Real Decreto-ley 22/77, de 18 de marzo, sobre Normas Electorales, la naturaleza urgente y sumaria del proceso especial, aquí seguido, conferido por la Ley $62 / 78$, en sus artículos $60^{\circ}$ y 10.1 , y la primordial protección que en él se persigue, conforme al artículo 53.2 de la Constitución española, no permite la aplicación de la causa c) del artículo 82 de la Ley Reguladora de esta Jurisdicción, invocada en apoyo de dicha inadmisibilidad, cuando tampoco, y como se apunta en la sentencia apelada, no se da en el caso, la exclusión expresa exigida por el artículo 40, apartado $f$ ), de la misma Ley Jurisdiccional. (Sentencia de la Sala IV del Tribunal Supremo de 14 de julio de 1982. Ponente: Excmo. Sr. D. Saturnino Gutiérrez de Juana.) 


\section{LIMITACIONES CAPACIDAD ELECTORAL PASIVA DE LOS MIEMBROS FUERZAS ARMADAS}

\section{Inelegibilidad salvo obtención de la situación de retirado o situación especial}

Que el artículo 3., 1 , en relación con el 2: ${ }^{\circ}, 1$, ambos del Real Decreto-ley 20/ 1977, de 18 de marzo, sobre Normas Electorales, dice que serán elegibles todos los españoles mayores de edad, incluidos en el censo electoral - con la dispensa que para este requisito establece el art. $3 .^{\circ}, 2$-, que se hallen en el pleno uso de sus derechos civiles y políticos, siempre que no se encuentren incursos en alguna de las causas de inelegibilidad a que se refiere el artículo $4 .^{\circ}$ de las mencionadas normas, entre las que se comprende, en lo que aquí interesa, la contenida en el apartado 1.d) del indicado artículo, relativa a los oficiales generales, jefes, oficiales, suboficiales y clases de tropa de los tres Ejércitos, Policía Armada y Cuerpo de la Guardia Civil, de acuerdo con lo previsto en el Real Decreto-ley 10/1977, de 8 de febrero, que con el propósito de mantener la neutralidad de los miembros de las Fuerzas Armadas respecto a las distintas opciones políticas, prohíbe, en su artículo 2. ${ }^{\circ}, 4$, a quienes con carácter profesional formen parte de las mismas, entre otras actividades, ejercer cargos públicos o aceptar candidaturas para los mismos cuando sean electivos y tengan carácter político o sindical, salvo que, como se establece en su artículo $5 .^{\circ}$, soliciten y obtengan el pase a la situación de «retirado», si se trata de jefes, oficiales, suboficiales y clases profesionales, o a la «situación especial», creada por el mencionado Real Decreto-ley, si se trata de oficiales generales.

Que esta regulación de la capacidad electoral pasiva, y concretamente en relación con los miembros de las Fuerzas Armadas, es en lo sustancial conforme con lo que posteriormente ha venido a establecer la Constitución al proclamar en su artículo 68.5 el principio de que «son electores y elegibles todos los españoles que estén en el pleno uso de sus derechos políticos», e igualmente con el contenido mínimo que en materia de inelegibilidades (e incompatibilidades) de diputados y senadores impone el artículo 70 del texto constitucional a la futura Ley Electoral, en cuanto que ésta deberá comprender, en todo caso, a los «militares profesionales y miembros de las Fuerzas y Cuerpos de Seguridad y Policía en activo». (Sentencia de la Sala III de lo Contencioso-Administrativo de la Audiencia Nacional de 14 de octubre de 1982. Ponente: Excmo. Sr. D. Angel Rodríguez García.)

2. No procede negar capacidad electoral pasiva a candidato, miembro Fuerzas Armadas, condenado por sentencia penal no firme, que ba solicitado pase situa. ción retirado. Naturaleza reglada del otorgamiento dicha situación. Improcedencia denegación expresa de pase a retirado por razones oportunidad politica. El artículo 117.1 de la Constitución impide reconocimiento efectos a un acto administrativo que discrimina a un candidato al estar viciado de nulidad radical como contrario a un derecho constitucional

Que ni la Junta Electoral Provincial de Madrid ni el Ministerio Fiscal, que ostenta, a tenor del artículo 73.4 del Real Decreto-ley 20/1977, la representación pública y la defensa de la legalidad, cuestionan que el candidato se encuentre en el pleno uso de sus derechos políticos, no obstante su situación de procesado por un delito de rebelión militar en causa $2 / 81$, en la que ha recaído sentencia dictada por el Consejo Supremo de Justicia Militar condenándole a la pena de treinta años de reclusión y que ha sido recurrida ante el Tribunal Supremo; es más, la Junta Electoral, al motivar la exclusión del mencionado candidato, razona que no 
sería obstáculo a su proclamación la sentencia dictada por el Consejo Supremo de Justicia Militar al no haber adquirido firmeza; lo que sí se aprecia por la Junta, para negar capacidad electoral pasiva al candidato excluido, es la concurrencia en él de una causa de inelegibilidad, concretamente continuar siendo miembro en activo de las Fuerzas Armadas, por haberle sido denegada por el señor ministro de Defensa, en resolución de 3 de septiembre último, su petición de pase a la situación de «retirado», que impide, a juicio de la Junta, que pueda ser proclamado como candidato al Congreso de los Diputados en tanto esta resolución no sea revocada.

Que esta tesis, compartida por el Ministerio Fiscal al sostener que habiéndose producido una resolución expresa denegatoria de la petición del candidato no proclamado debe estarse a lo resuelto, sin perjuicio de los recursos que el interesado pueda interponer en las vías pertinentes, y que la parte recurrente combate, por entender que la solicitud de retiro presentada está equiparada legalmente al retiro mismo, por imperativo del artículo 9. del Real Decreto 706/1977, de 1 de abril, constituye el núcleo del recurso, cuya valoración no puede hacerse sin tener en cuenta un dato que la Sala estima esencial, cual es que entre la publicación del Real Decreto-ley 10/1977, sobre actividades políticas y sindicales de los miembros de las Fuerzas Armadas y su desarrollo por Real Decreto $706 / 1977$, se produjo la promulgación del Real Decreto-ley 20/1977, sobre Normas Electorales, en cuyo artículo $4 .^{\circ}, 3$ se fija un plazo breve y perentorio para la calificación de las causas de inelegibilidad respecto de quienes fueren titulares de los cargos mencionados en sus apartados 1 y 2, concretamente, el octavo día posterior a la publicación del decreto de convocatoria de elecciones (o en cualquier momento posterior hasta la celebración de éstas); aquí puede hallarse la clave de que el artículo 9.0,4 del Real Decreto 706/1977, al desarrollar el artículo 5. del Real Decreto-ley 10/1977, diga que, presentada la solicitud de pase a las situaciones previstas en el indicado artículo 5. - «retirado» y «situación especial»-, se entenderá concedido el pase a la nueva situación al efecto de poder ejercer las actividades, cargos o inclusión en candidaturas de carácter político o sindical, sin incurrir en responsabilidad, lo que queda corroborado si se repara en que el pase a la situación de «retirado», a petición propia, no está sujeto a condicionamiento legal alguno, como puede inferirse de los artículos 14 del Real Decreto 734/1979, de 9 de marzo, sobre situaciones militares, y 12 de la Orden de 31 de julio de 1981, y a un rango normativo superior, de los artículos 211 y 223 de las Reales Ordenanzas de las Fuerzas Armadas, aprobadas por Ley 85/1978, de 28 de diciembre, el primero de los cuales es bien expresivo al decir que «todo militar que acepte ser designado para el desempeño de una función pública, se presente a elecciones para órganos representativos o participe de cualquier otro modo en la dirección de los asuntos públicos, pasará a la situación que señale la ley, que determinará los efectos que por tal causa se derivan para su carrera».

Que no obstante todo lo anterior, podría argüirse, y así lo hace el Ministerio Fiscal, que los efectos ex lege que el artículo 9.0,4 del Real Decreto 706/1977 anuda a la presentación de la solicitud de pase a la situación de «retirado» cesan cuando se dicta, como ha ocurrido en el caso de autos, la orden decisoria y en ella se deniega la petición presentada, y, siguiendo esta misma línea argumental, sostenerse, como también lo hace el Ministerio Fiscal, que dictada la Orden de 3 de septiembre de 1982 por la que se deniega el pase a la situación de «retirado» para dedicarse a la actividad política y encabezar una candidatura, ha de estarse a su contenido, sin perjuicio de los recursos que el interesado pueda interponer contra dicho acto en la vía pertinente, y que el señor ministro de Defensa concretó en el recurso de reposición como previo al contencioso-administrativo; mas frente a esta argumentación, que implícitamente niega a la Sala toda posibilidad de análisis sobre la legalidad de la Orden de 3 de septiembre de 1982, ni siquiera 
como cuestión previa a su indeclinable deber de pronunciarse sobre la validez o invalidez de la exclusión del candidato no proclamado, hemos de afirmar que el sistema de control judicial instaurado por el Real Decreto-ley 20/1977 para asegurar, como revela su preámbulo, la defensa de la legalidad en todo el proceso electoral, comporta el conocimiento y decisión, a los efectos del recurso contencioso-electoral, de aquellas cuestiones que surgiendo con ocasión de un acto administrativo dictado dentro de dicho proceso, pueden ser determinantes, como en el caso que se enjuicia, de la validez o invalidez de la no proclamación de un candidato, pues parece que la remisión de este tema a las vías impugnatorias ordinarias, como único cauce para dilucidar la legalidad de la Orden de 3 de septiembre de 1982, equivaldría a una negación de las funciones legalmente atribuidas a la Sala y a dejar de facto en manos de la Administración, por el juego de los plazos preclusivos del procedimiento electoral, el control de la legalidad de la no proclamación de un candidato, lo que sería contrario al espíritu que anima la regulación del recurso contencioso-electoral.

Que entrando a examinar, por tanto, a los solos efectos de la decisión de este recurso, la legalidad del acto ministerial de 3 de septiembre de 1982, con lo que ya se ha adelantado ha quedado acreditada la ausencia de condicionamiento legal obstaculizante del pase a la situación de «retirado» del candidato no proclamado, pero no quedaría completo el análisis de la legalidad de dicha resolución si no examináramos los argumentos que se recogen en la motivación de ésta y que no hayan sido ya valorados como consecuencia de los razonamientos anteriores; así, se invoca en el calendado acto administrativo la situación de «procesado» y condenado del peticionario por el Consejo Supremo de Justicia Militar a la pena de treinta años de reclusión como autor de un delito de rebelión militar, cuya sentencia ha sido recurrida ante el Tribunal Supremo, para razonar que perdura la situación de procesado y que ella lleva consigo el cese en los cargos, mandos, destinos o comisiones que desempeñe aquél, efectos estos que ciertamente señalan los artículos 9 del Real Decreto 734/1979, de 9 de marzo, y 11 de la Orden de 31 de julio de 1981, pero que obviamente carecen de efecto causal en relación con la petición deducida, sin que se revelen las razones jurídicas de estas citas legales en relación con la decisión adoptada; se invoca también el artículo 182 de las Reales Ordenanzas de las Fuerzas Armadas, que impone a todo militar un deber de neutralidad frente a las distintas opciones políticas o sindicales, con la consiguiente prohibición de participar en actividades de esta naturaleza, pero se omite que el artículo 211 de las mismas Reales Ordenanzas, del que ya hemos dejado constancia, prescribe que todo militar que acepte ser designado para el desempeño de una función pública, se presente a elecciones para cargos representativos -que es lo que postulaba el interesado - o participe de cualquier otro modo en la dirección de los asuntos públicos, pasará a la situación que señale la ley; por último, conectando la condición de procesado del solicitante y la naturaleza del delito por el que ha sido condenado con la petición de pase, implícita o explícita, a la situación de «retirado» para dedicarse a la actividad política encabezando una candidatura para las próximas elecciones generales, se arguye que si se accediera a lo pretendido - se prescinde de la referencia a la pretendida infracción de los preceptos legales que se citan, pues ya ha quedado analizado este punto- se atentaría contra la propia esencia de las Fuerzas Armadas, que como dicen los artículos 3 y 10 de las Reales Ordenanzas, forman una institución disciplinada, jerarquizada y unida, cuya misión es garantizar la soberanía e independencia de la Patria, defender la integridad territorial y el ordenamiento constitucional.

Que cuando así se arguye se están invocando, bajo la aparente cobertura de unos preceptos legales que definen nuestras Fuerzas Armadas y fijan, de conformidad con el artículo 8 de la Constitución, la misión de las mismas, razones de oportunidad política para denegar el pase del peticionario a la situación de «reti- 
rado», con la consiguiente imposibilidad de concurrir como candidato a las próximas elecciones generales, sin reparar que la situación administrativa solicitada es materia reglada, que está minuciosamente regulada cuando, como hemos visto, el pase a ella se solicita para dedicarse a actividades políticas o para aceptar candidaturas para cargos públicos electivos; la Sala es consciente de la gravedad y trascendencia de los hechos que se imputan en la sentencia dictada por el Consejo Supremo de Justicia Militar en la causa 2/81, pero también lo es del insoslayable deber que tiene, y que le impone el artículo 117.1 de la Constitución, de someter sus decisiones al imperio de la ley, que impide el reconocimiento de efectos a un acto administrativo que al discriminar a un candidato a las próximas elecciones generales está viciado de nulidad radical como contrario a un derecho constitucional fundamental (sentencia del Tribunal Constitucional de 22 de diciembre de 1981), el derecho reconocido en el artículo 23.2 de la Constitución, que establece la igualdad de todos los ciudadanos en el acceso a los cargos y funciones públicos, con los requisitos que señalan las leyes. (Sentencia de la Sala III de lo Contencioso-Administrativo de la Audiencia Nacional de 14 de octubre de 1982. Ponente: Excmo. St. D. Angel Rodríguez García.) 